\title{
Chysiology \\ TO STUDY THE EFFECT OF EXERCISE ON PHYSICAL FITNESS OF HEALTHY MEDICAL STUDENTS AND TRAINED ATHLETES USING STEP TEST.
}

\section{Dr Rituparna Bora}

Dr Utpal Dutta*

\section{Assistant Professor ,Department of Physiology.,Assam Medical College, Dibrugarh.}

Assistant Professor ,Department of Anaesthesiology,Assam Medical College,Dibrugarh *Corresponding Author

ABSTRACT INTRODUCTION : Physical fitness implies the ability to make adequate physiological adjustments to the stresses maintain continuous activity.

imposed by a specific task. Good cardiorespiratory function is reflected by the ability to deliver oxygen to the tissues to

MATERIALS AND METHODS : The present study was carried out to study the effect of exercise on the physical fitness of healthy young adults. Exercise stress test was done by Harvard step test. Study population comprised of 100 young adults with subset of 50 trained athletes and 50 sedentary healthy adults. The parameter for measuring Physical fitness was Physical Fitness Index.

RESULTS: Mean value of PFI in trained athletes and sedentary healthy adults were 85.42 and 72.79 respectively i.e., mean value of PFI is higher in trained than sedentary group. This is statistically highly significant $(\mathrm{P}$ value $<0.001)$.

CONCLUSION: The study reveals that physical fitness is high in trained athletes than the untrained group. There is a need for inclusion of regular exercise in medical students to attain high level of physical fitness.

KEYWORDS :Physical fitness index, Harvard step test, trained athletes.

\section{INTRODUCTION}

Exercise for the body is regarded as the foundation for good health in terms of physical and psychological wellbeing. Increased physical activity and avoiding a sedentary life style can decrease the incidence of cardiac disease, hypertension, diabetes mellitus, osteoporosis and coronary heart disease. It contributes to the reduction in mortality and morbidity. It also improves the quality of life. It has been seen that there are many benefits of exercise, so exercise needs to be prescribed as one prescribes drugs.

Exercise enhances body's ability to utilize oxygen. A physically fit person tends to have a lower pulse rate and blood pressure level after a given amount of work than a person leading a sedentary lifestyle. Regular exercise reduces the energy requirements of the heart muscle.

Exercise testing is being increasingly used to estimate and improve the cardiovascular health, determine functional capacity of cardiovascular system, assess the probability and extent of coronary heart disease and also to monitor the level of physical fitness so that preventive measures for a person can be taken. Physical fitness is required not only by athletes for better performance but also by nonathletes for maintenance of physical and mental health. Heavy academic workloads in medical education make it difficult for medical students to maintain a regular exercise program. Physical Education provides a great variety of activities and high intensity exercises for students. Hence, the current study was undertaken to compare physical fitness of trained athletes with Medical students. The medical students of today are physicians of tomorrow and a good physician must be physically fit and mentally alert

\section{MATERIALS AND METHODS}

A cross sectional study was conducted on 100 healthy young adults (17 to 25 years of age), 50 of them MBBS Students of our college and 50 of them were trained athletes of a sports club of Milan Jyoti Sangha Dibrugarh. The detailed procedure was explained as well as demonstrated to the participants in advance. The study was conducted in the Department of Physiology of Assam Medical College Dibrugarh.

\section{INCLUSION CRITERIA:}

1. Healthy young male and female medical students and trained athletes of Milan Jyoti Sangha Dibrugarh.

2. Age group: 17 to 25 years

\section{EXCLUSION CRITERIA:}

1. History of any disorders like diabetes mellitus, hypertension, bronchial asthma, cardiovascular disorders.

2. History of alcohol intake, smoking habits and tobacco addicts.

3. History of any drug intake.

4. Undergone major surgery.
5. Locomotor and musculoskeletal abnormalities.

6. Presence of obesity, anaemia and chronic diseases.

7. Any endocrine disorders were excluded from the study.

\section{PROCEDURE:}

Physical fitness index of each subject was recorded by using Harvard step test with step height of 20 inches. The subjects were asked to be lightly clothed. They were asked to take rest for $5 \mathrm{~min}$, thereafter they were asked to perform the stepping exercise on 20 inches high step without shoes. The step used was a heavy wooden step, so that it remained steady during the test. The subject stepped up and down the steps 30 complete steps /minute (1 step every 2 seconds). As the signal starts, the subject places one foot on the platform, steps up places other foot on the platform, straightens both legs and the back bone and then step down bringing down the same foot that he placed up first. The subjects were directed to lead off with the same foot each time and not the alternate foot. Subject performed this exercise as long as he/she could, but not in excess of $5 \mathrm{~min}$. After the cessation of exercise, the subjects were made to sit quietly on a chair. After exact 1 minute, the pulse rate was recorded for 30 s with the help of stop watch.

\section{PRECAUTION:}

If the subject was dyspnoeic, felt exhausted or felt pain in chest or legs during the exercise, he was asked to discontinue the exercise immediately. The subject performed the exercise for $5 \mathrm{~min}$. unless he stopped earlier due to exhaustion. If the subject could not maintain the stepping rate of 30 times $/ \mathrm{min}$. for $20 \mathrm{~s}$, he was assumed to be exhausted and the step-test was discontinued.

At the end of 5 minutes the heart beats are recorded at three different time intervals in sitting position. The change in heart rate at Time 1 or Pulse 1(PR1), Time 2 or Pulse 2(PR2) and Time 3 or Pulse 3 (PR3) shows the person's recovery time after the exercise. That is how quickly the person's heart rate returns to its normal resting rate after exercise.

The Physical Fitness Index is calculated by using following formula $\mathrm{PFI}=$ Duration exercise (in sec.) X 100/2 (PR1 + PR2 + PR3) Scoring is done as

\begin{tabular}{|c|c|}
\hline STEP TEST SCORE & RATING \\
\hline$>90$ & Excellent \\
\hline $80-89$ & Good \\
\hline $65-79$ & High average \\
\hline $55-64$ & Low average \\
\hline$<55$ & Poor \\
\hline
\end{tabular}

\section{RESULTS:}

Table 1: Shows the comparison of recovery heart beats between trained athletes and medical students. There is a significant difference of recovery heart rate between the two groups 


\begin{tabular}{|l|c|c|}
\hline \hline GROUP & NO OF CASES & $\begin{array}{l}\text { TOTAL OF HEART } \\
\text { BEATS TAKEN IN } \\
\text { THE RECOVERY } \\
\text { PERIODS }\end{array}$ \\
\cline { 3 - 3 } & & MEAN \pm SD \\
\hline TRAINED & 50 & $175.18 \pm 10.13$ \\
\hline UNTRAINED & 50 & $207.72 \pm 20.34$ \\
\hline \multicolumn{2}{|c|}{ SIGNIFICANCE } & Very highly significant \\
\hline \multicolumn{2}{|c|}{ P VALUE } & $<0.001$ \\
\hline
\end{tabular}

TABLE 2: Shows the comparison of PFI between trained group and Medical students. There is a significant difference of PFI between the two groups.

\begin{tabular}{|l|c|c|}
\hline GROUP & NO OF CASES & $\begin{array}{l}\text { PHYSICAL FITNESS } \\
\text { INDEX (PFI) }\end{array}$ \\
\cline { 2 - 3 } & & MEAN \pm SD \\
\hline TRAINED & 50 & $85.42 \pm 4.74$ \\
\hline UNTRAINED & 50 & $72.97 \pm 7.61$ \\
\hline \multicolumn{2}{|c|}{ SIGNIFICANCE } & Very highly significant \\
\hline \multicolumn{2}{|c|}{ P VALUE } & $<0.001$ \\
\hline
\end{tabular}

Thus the physical fitness assessed from Physical fitness Index of trained young athletes was very high compared to the medical students as obtained from the statistical significance $(\mathrm{P}$ value $<0.001)$.

\section{DISCUSSION:}

Physical fitness of medical students of Assam Medical College is not satisfactory due to lack of sporting activity and sedentary lifestyle. Heart rate variability is less among physically fit individuals. So, regular exercise and nutritious diet under guidance increases the physical fitness.

Advantages of Harvard step test: This test requires minimal equipment and costs, and can be self-administered.

Disadvantages: Biomechanical characteristics vary between individuals. For example, considering that the step height is standard, taller people are at an advantage as it will take less energy to step up onto the step.

Thus, it can be concluded that regular physical activity is an important determinant of physical fitness.

\section{REFERENCES:}

1. Montoye HJ. The Harvard step test and work capacity. Rev Can Biol 1953;12:37-41

2. "Assessing Physical Fitness of participants and staff".American Journal of Epidemiology 143:228-239,1996

3. Fauci Anthony S .et .al.Principles of Disease prevention,Disorders of the cardiovascular system.Harrison's Principles of Internal Medicine.47,1398,Vol-1,14 th Edition, 1998

4. Bijlani RL. Physiology of exercise. Understanding medical physiology. A textbook of Bijlani RL. Physiology of exercise. Understanding medical physiology.
medical students. New Delhi: Jaypee Brothers 2004;3rd edn:p.636-49.

5. Banerjee PK, Chatterjee S. Harvard step test as a measure of physical fitness in adolescent boys. Ind J med Res 1983;79:413-417

6. Ryhming I. A modified Harvard step test for the evaluation of physical fitness. Arbeits Physiologie 1953;15(3):235-50.

7. Sunil KR, Das SK, Mahapatra S. Determination of physical fitness index (PFI) with modified Harvard step test (HST) in young men and women. Ind J Physiol and Allied sci 1993;47(2):73-76.

8. Clarke HH. Basic understanding of physical fitness. Physical fitness research digests series 1971;1:2.

9. Shrivastav S, Dhar U, Varun Malhotra. Correlation between physical fitness and body mass index IJCRR 2013;5(23):44-48. 